\title{
A study of inverted classroom pedagogy in computer science teaching
}

Reza, Sameen

Department of Computer Science, Virtual University of Pakistan, Pakistan (sameen_reza@yahoo.com)

Ijaz Baig, Maria $\bowtie$

Department of Computer Science, Virtual University of Pakistan, Pakistan (mariaijazbaig@ hotmail.com)

Received: 30 January 2015

Available Online: 19 May 2015

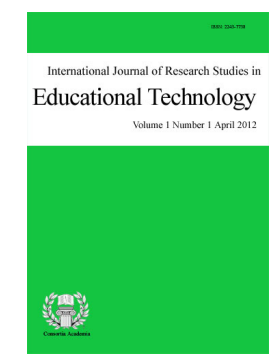

ISSN: $2243-7738$ Online ISSN: 2243-7746

OPEN ACCESS

\section{Abstract}

An "inverted classroom" is a teaching environment that integrates the use of technology with active learning by exploration. In such a teaching environment, the class contact time is used for learning by doing whereas passive teaching is done out of class through the use of some communication medium (video lectures, or web-based content). The aim of this study is to investigate the inverted class room pedagogy in teaching undergraduate computer science course. Its primary objective is to help in bridging the gap of knowledge pertaining to use of technology and its effectiveness within the context of undergraduate computer science education. The course selected for this study is that of Data Structures offered at undergraduate level at a Pakistani university. This study employs the use of the Quasi-Experiment, two groups (Control and Treatment) - Pre-test and Post-test design model of experimentation. Key deductions of this study are that use of inverted class room pedagogy has positive impact on the learning outcomes. Students, who were participants of this experiment, showed a higher knowledge gain than their control group counterparts. This difference is especially pronounced in the areas of problem solving and programming ability. The results from this study can be used to transform other traditional computer science courses to inverted form. Inverted class room pedagogy shows the potential to address issues of student disinterest, lack of motivation and lagging attendance.

Keywords: blended learning; inverted classrooms; pedagogy; data structures; hybrid 


\section{A study of inverted classroom pedagogy in computer science teaching}

\section{Introduction}

A paradigm shift from behaviorist to constructivist approach has transformed the role of the teacher from the "sage on the stage" to a "guide on the side" (Lage et al., 2000). Emphasis is now placed on active learning where the learner constructs a particular perspective of things. Foreman (2003) summed up the necessary fundamentals of learning by stating "that the ideal learning situation is customized, provides immediate feedback, is constructive, motivates students to persist, and builds enduring conceptual structures". Typical classroom lecturing fails on most of these aspects as teachers dominate the classroom environment leaving the students to have a passive role. This is especially pronounced in the higher education sector where class sizes are large with limited contact time per week and extensive subject matter that is to be covered in 15-17 weeks of the semester. Traditional classroom instruction is combining the use of online instruction giving way to a new "hybrid" form of instruction that is a blend of both (Hiltz \& Turrof, 2005). Blended learning is a new concept that has emerged as an amalgamation of distance learning, online education and typical class room learning (Gal-Ezer, 2009).

An "inverted class room" is a new educational pedagogy that is a manifestation of blended learning. Here the use of technology allows better utilization of class time as students go through the passive elements of the lecture before coming to class. Instructors utilize class time for guiding students to solve practical problems on the content that has been covered. Thus active learning of student replaces passive listening. Using this methodology students get a chance to practice in class what they have understood beforehand. Teachers also get a chance to focus on the students learning and can cater to each student's problem individually (Lage et al., 2000).

The most common problem reported by students of Computer Science (CS) discipline is their inability to transform their theoretical knowledge into practical skills (Garner et al., 2005). A lot of focus of research in Pakistan has been on curriculum development for the CS discipline however none of the researches focus on the way these can be taught in the most effective way. The use of inverted classrooms has been applied in a lot of courses that were taught at tertiary level in developed countries. They have been seen to improve student learning especially when applied to courses that have a practical nature.

\subsection{Significance of the study}

This study was taken up to see how effective is the inverted classroom methodology in the context of higher education computer science courses taught in Pakistan. It helped to discover the outcome of converting conventional instructor led courses to inverted class rooms. It investigated if the use of technology to supplement the traditional teaching produced better learning outcomes. A side benefit of this study was an exploration of how students like the idea of studying in an inverted class room. Using this research, the concept of inverted classrooms can be expanded to other Computer science courses at Pakistani universities.

\section{Literature review}

The term inverted classroom was first coined in 2000 in an experiment of the use of this methodology in an economics course (Lage et al., 2000). The study reports that this format of a class was preferred by students and their perception was that they learnt better as well. Subsequently, multiple experiments of replacing large lectures with provision on online course material were performed (Scheines et al., 2005). These involved six hundred students, three different lecturers, six different recitation instructors, and two different locations over a course of 5 experiments. The most important conclusion from this research was that this replacement of lecture proved to be quite beneficial. Scheines et al. (2005) found the correlation to be more than 0.8 between proportion 
of voluntary comprehension checks attempted and the average module quiz score from data from two universities. Day and Foley (2006), at Georgia Tech University used this methodology with a course on Human Computer Interaction. Results of this Quasi-Experiment indicated that the students performed better on the average than those in the traditional class room.

Inverted classrooms were also utilized in the course of software engineering curriculum at Miami University (Gannod et al., 2008). Results of surveys indicated that $56 \%$ of the students were of the opinion that podcasts should supplement rather than replace lectures. Inverted classrooms offer immediate feedback and more contact time to students as compared to Traditional classroom (Table 1). Also, in terms of learning activities, Inverted classrooms provide more assignments although the depth of each assignment is less (Table 2). This study recommended the use of the same strategy with the course of Data Structures as being a programming intensive course, the strategy of using inverted classes will give more time to students for hands on practice. Thille (2010) performed a study on delivery through hybrid methods at Carnegie Mellon University which revealed that the students learnt the same material successfully in half the time, as required through traditional methods. Carrington et al. (2010) compared the delivery of a course on Software Engineering through two different tools (Blackboard and Wimba) as collaboration techniques using the blended learning approach. Use of collaboration techniques was deduced to be beneficial and recommended for achievement of learning goals. Carlisle (2010) experimented with the idea of inverted class rooms with a slight variation in a programming course by providing short videos on YouTube that to the students before the class. Overall, the result showed a positive result of these videos on student motivation, student preparation and test. Benefits of using this pedagogy in light of literature review can be summarized as:

- Liberation of Class time: This time is used for focusing on students' learning rather than lecture delivery (Scheines et al., 2005).

- Push and Pull Effect: Passive learning is pushed from and active learning is pulled into the classroom (Gannod et al., 2008).

- Course Coverage: More course content can be covered in lesser time (Thille 2010).

- Instructor engagement with student: In an inverted class room the instructor is more engaged with struggling students rather than the successful ones in contrast to traditional classrooms (Lage et al., 2000).

- Opportunity of Experimentation: Instructors can use a variety of styles without disturbing the course schedule and coverage of content (Lage et al., 2000).

- Females performed better in the inverted class room environment (Lage et al., 2000).

However, some researchers also pointed out caution as inverted class rooms work best with a smaller class size. Recommended class size is not more than 40 students (Lage, et al., 2000). Inverted class rooms present additional workload to the students (McCray, 2000). However, the additional workload was offset by the breadth and depth of course content delivered. Fonseca et al. (2009) reported that an instructor's work load was considerably more in an inverted class room than in the traditional one.

Previous studies have established the overall effect of inverted classroom that is beneficial to teaching. However these were not applied to a Data Structures course in particular. In addition, they did not determine the exact areas where inverted teaching is found to be useful. This study has extended the previous researches by identifying that problem solving and programming are two key aspects where inverted classrooms provide greater benefit. Typically programming and problem solving subjects in Computer Science domain are considered tough by students and have a high dropout percentage as well. This research has provided justification that such courses should be converted to inverted form to reduce the occurrence of such observations. 
Reza, S., \& Ijaz Baig, M.

\section{Table 1}

Feedback and Contact in Inverted vs. Traditional Class Room

\begin{tabular}{ll}
\hline \multicolumn{1}{c}{ Traditional } & \multicolumn{1}{c}{ Inverted } \\
\hline Instructor feedback is delayed & Immediate Instructor feedback is available \\
Contact and guidance is limited to office hours & Contact during entire lecture hour \\
\hline
\end{tabular}

Table 2

Comparison of Learning Activities in Inverted and Traditional Class Room

\begin{tabular}{lll}
\hline & \multicolumn{1}{c}{ Traditional } & \multicolumn{1}{c}{ Inverted } \\
\hline Number of Assignments & Low & High \\
Outcome Coverage & Low & High \\
Feedback & Delayed & Immediate \\
Depth per Assignment & High & Low \\
\hline
\end{tabular}

\subsection{Research problem}

This study on Inverted class room has furthered the work of earlier researches by investigating its use for the course of Data Structures in CS discipline (Gannod et al., 2008). Review of the above literature has posed a question before us that whether this methodology would be as effective in the context of computer science teaching in Pakistan? How the use of technology could be investigated in undergraduate programming intensive courses and whether it could help struggling students. This article measures this effectiveness in terms of programming ability, theoretical knowledge and problem solving ability of students. The impact on student attendance and their perception of this experience is also gauged in this study.

\section{Research design}

This study is a mono method, cross sectional study and was conducted in the fall term of the academic year. It is a quantitative research using Quasi Experiment, Pre-test and Post-test design model of experimentation.

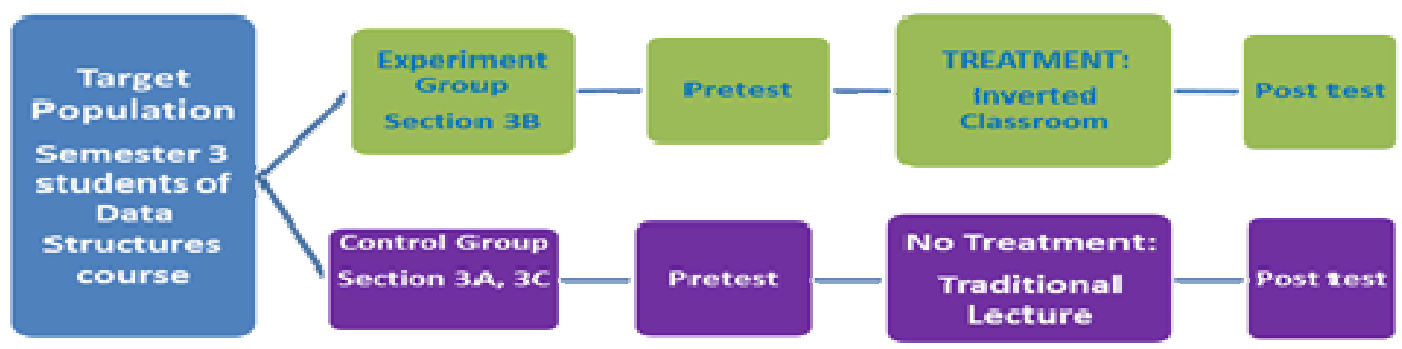

Figure 1. Research Setting of the Study

\subsection{Population}

The population of this experiment comprises the students of Shaheed Zulfikar Ali Bhutto Institute of Science and Technology, enrolled in the Bachelors of Science in Computer Science program. The Data Structures course, on which this quasi experiment was conducted, is offered to students of semester III. Students of this course were pre-divided into three sections out of which arbitrarily it was decided that Sections A and C formed the control group while section B was the experiment group.

\subsection{Sample size}

Size of treatment group was 23 students (Section B) while size of control group was 42 students (Combined 
Sections A and C).

\subsection{Sampling Technique}

No specific sampling technique could be applied as the sections are pre decided by SZABIST management and neither the researcher nor any faculty member can assign a student to a section. The selection of treatment group was arbitrary. That is the reason that this study is a Quasi-Experiment. However, as the assignment of students to each section is completely arbitrary therefore sampling technique can be said to be randomized.

\subsection{Measurement/Instrument Selection}

The instrument used to measure the learning outcome quantitatively was the students' score on a pre-test and a post-test. The pretest was conducted prior to start of treatment while the post test was conducted after the end of treatment. Both the pre-test and the post-tests were designed to measure the knowledge and competency in three areas, namely: theoretical knowledge and concepts, programming ability, competency in solving problems. These areas are defined as follows:

- Programming Ability: Students skill in being able to formulate the logic and syntax of the computer program

- Theoretical knowledge: The concepts and theory necessary for understanding the core principles of the course

- Problem Solving Capability: Ability to assimilate and apply knowledge gained to real life problems and scenarios

The pre and post-tests of the students were marked on these criteria to evaluate the how the effect of inverted class rooms had manifested itself into these outcomes. The tool used to assess the motivation of students was a questionnaire (see Appendix) filled in by the students at the end of the term. Attendance was calculated using their daily attendance roster. Comparison of attendance of students that were in the control group with those of experimental group also served to check if students of inverted class rooms were more motivated to attend classes than regular students.

\subsection{Reliability and Validity of the Instrument}

The pre-test was prepared by using materials used to assess computer science students by experienced teachers. Thus it adequately examined the students in the relevant areas. Similarly the post-test was also prepared using materials used to assess Data structures students by expert teachers. A group of data structure course teachers were asked to assess the quality of the post-test. After quite some modifications and rectifications, the post-test was approved by these teachers to be sufficient for assessment of students in the areas of programming, problem-solving and theoretical knowledge. Questionnaire that gauged the students experience in the course was also shown and approved by three different statisticians.

Another feature that yields reliability to this study is that the cohort of students was pre-tested before the treatment and the results of this pre-test were tabulated and analyzed before the start of treatment. The treatment of inverted classroom was initiated only because the pre-test results showed that both the control and the experiment group had comparable ability. Therefore it could be ascertained without doubt that a difference in ability in the post test could only be the result of the treatment extended to the control group.

In addition although the students were not picked randomly per section for the control and experiment groups, however this disadvantage is also offset by the fact that SZABIST assigns a student to section randomly only once which is at admission time. Later they do not have the choice of changing their sections. So in this background, the assignment of a student to a section is randomized therefore the results of this study are safe 
Reza, S., \& Ijaz Baig, M.

from bias.

\subsection{Details of Pre-test}

An identical pre-test was given to both groups before the start of the course to determine if the two groups can be considered to have equal ability. Analysis of the pre-test revealed that both the groups had comparable ability in the three areas that were gauged by the pre-test. Therefore any improvement in the post-test could only be attributed to the treatment provided to the experiment group.

\subsection{Instruction methodology}

The control group was taught the course of Data Structures, using the traditional lecture methodology. Using this methodology, students were introduced to the concept of each day's lecture by the teacher during class time. In each lecture, they were given home assignments. These were checked subsequently by the teacher after class time and feedback provided to the students. The solution to these assignments was discussed in class after they were marked. During the course of the semester, these students were assessed through multiple quizzes, a midterm exam, several marked assignments and a final exam. As the course was taught by a full time teacher, therefore these students had access to the teacher during office hours apart from regular class time. To further assist their understanding, study resources were provided through a learning management system to these students but these were available only once the students had been introduced to the main topic in class.

The experiment group students were taught in a different manner. The study material relevant for each next class was posted on a website in the beginning of each week. Students were asked to pre-read this material relevant for the next class. Once in class, students were first given a very trivial 5 marks quiz to test whether they actually went through the material provided. The marks of these quizzes were added up as their pre preparation score. Next, these students were given the day's assignment on the topic of concern and were asked to find the solution. This assignment was identical to the one give to students of the control group. This activity enhanced the understanding of the material. When the students were puzzled or stuck, the teacher attended to the student and explained that part of the content that was hampering the progress of the student. Thus instruction was personalized and provided in an on-demand manner. Instruction of the course continued in this manner till the end of semester. Attendance of students in both groups was recorded in each class. This was accumulated at the end of the semester in the attendance roster.

\subsection{Post-test}

At the end of the experiment, the two groups were administered the same post-test. This served to prove if the treatment had any effect on the learning outcomes. At the end of the experiment, students were also given a questionnaire to gauge their perception of the inverted classroom methodology. This questionnaire was based on Likert scale and had 3 items which were evaluated through 11 questions (see Appendix).

\subsection{Variables}

- Pre preparation Score (Scores on quizzes taken to gauge pre class effort of experiment group students)

- Scores of the students on the post-test (Total Score, Programming Ability Score, Problem Solving Score and Theoretical Knowledge Score)

- Student attendance percentage

- Student experience of the inverted class room methodology 


\subsection{Hypotheses}

The research hypotheses were formulated as follows:

H1: Overall level of achievement is higher in students of inverted classrooms.

$\mathrm{H} 2$ : Programming ability of inverted classroom students is better.

H3: Gain in theoretical knowledge is more for inverted classroom students.

H4: Problem Solving Ability of inverted classroom students is more enhanced.

H5: Class Attendance in inverted classrooms is better.

H6: Pre preparation positively affects overall learning.

H7: Students have a positive experience of inverted classrooms.

\subsection{Method of Analysis and Statistical Tools}

The pre-test scores were analyzed using two sample t-test. A two-tailed test was applied on pre-test score. The purpose was to compare the two groups prior to any instruction was imparted to see if they were equal in ability. The post-test scores were analyzed using a two sample t-test. Here a one tailed test was applied. The purpose was to see if experiment group students performed better than control group students. MS Excel was used to perform data analysis.

\section{Results}

\subsection{Pre-test Analysis}

Application of t-test of independent groups showed (Table 3) that the students had similar ability and potential in all three areas (Programming Ability, Problem Solving and Theoretical Knowledge). The null hypothesis was accepted that stated that there was no significant difference in the programming ability, theoretical knowledge or problem solving ability of students in the two groups prior to the treatment.

Table 3

Pre-test Results

\begin{tabular}{lccccc}
\hline Pre-Test Result Categories & $\begin{array}{c}\text { Mean } \\
\text { Control } \\
\text { Group }\end{array}$ & $\begin{array}{c}\text { Mean } \\
\text { Experiment } \\
\text { Group }\end{array}$ & $\begin{array}{c}\text { SD } \\
\text { Control } \\
\text { Group }\end{array}$ & $\begin{array}{c}\text { SD } \\
\text { Experiment } \\
\text { Group }\end{array}$ & $\begin{array}{c}p(\mathrm{~T}<=\mathrm{t}) \\
\text { two-tail } \\
\alpha=0.05\end{array}$ \\
\hline 1. Programming Ability & 3.80 & 3.76 & 1.153 & 1.37 & 0.909 Accepted $(p>\alpha)$ \\
2. Problem Solving Skills & 2.36 & 2.41 & 0.971 & 0.973 & 0.825 Accepted $(p>\alpha)$ \\
3. Theoretical Knowledge & 1.45 & 1.50 & 0.679 & 0.657 & 0.785 Accepted $(p>\alpha)$ \\
4. Total Score & 7.61 & 7.67 & 2.335 & 2.746 & 0.918 Accepted $(p>\alpha)$ \\
\hline
\end{tabular}

Table 4

Post-test Results

\begin{tabular}{lccccc}
\hline Post-Test Result Categories & $\begin{array}{c}\text { Mean } \\
\text { Control } \\
\text { Group }\end{array}$ & $\begin{array}{c}\text { Mean } \\
\text { Experiment } \\
\text { Group }\end{array}$ & $\begin{array}{c}\text { Variance } \\
\text { Control } \\
\text { Group }\end{array}$ & $\begin{array}{c}\text { Variance } \\
\text { Experiment } \\
\text { Group }\end{array}$ & $\begin{array}{c}p(\mathrm{~T}<=\mathrm{t}) \\
\text { One-Tail } \\
\alpha=0.05\end{array}$ \\
\hline 1. Programming Ability & 5.07 & 6.63 & 2.746 & 2.706 & 0.016 \\
2. Problem Solving Skills & 2.10 & 3.00 & 1.619 & 1.349 & 0.013 \\
3. Theoretical Knowledge & 5.12 & 7.00 & 5.441 & 5.692 & 0.097 \\
4. Total Score & 12.3 & 16.6 & 8.006 & 8.136 & 0.021 \\
5. Attendance & 88.5 & 93.9 & 8.367 & 5.568 & 0.001 \\
\hline
\end{tabular}


Reza, S., \& Ijaz Baig, M.

\section{Table 5}

Post-test Results

\begin{tabular}{lc}
\hline \multicolumn{1}{c}{ Post -Test Result Categories } & Null Hypothesis \\
\hline 1. Programming Ability & Rejected $(p<\alpha)$ \\
2. Problem Solving Skills & Rejected $(p<\alpha)$ \\
3. Theoretical Knowledge & Accepted $(p>\alpha)$ \\
4. Total Score & Rejected $(p<\alpha)$ \\
5. Attendance & Rejected $(p<\alpha)$ \\
6. Effect of Pre preparation on Total Score & $\mathrm{r}=0.846$ Positive Co-relation exists \\
& Course Experience $\mu=3.63$ \\
7. Student Feedback & Learning Effectiveness $\mu=3.49$ \\
& Pre preparation Quality $\mu=3.68$ \\
\hline
\end{tabular}

\subsection{Post-test Analysis}

Post-test was conducted after instruction of the course. The test was of 30 marks 10 of which were based on programming ability questions, 15 on theoretical knowledge and 5 on problems solving skill questions. The scores were tabulated in these four categories (Table 4). The t-test for independent samples was applied on the post-test scores. Results (Table 4) for programming ability and problem solving ability showed students in inverted class rooms performed significantly better than the traditional class room students in these two areas. The difference was not that significant as far as the area of theoretical knowledge was concerned. Thus the null hypothesis was rejected in the first two cases in favor of the alternate one (Table 5). The Pre preparation Score was plotted against the total post test score of the students. A positive co relation was seen that established that a more effective use of the study material resulted in a better post-test performance (Figure 2) with $r=0.846$ (Table 6).

\section{Table 6}

Correlation between Pre Prep and Total Score

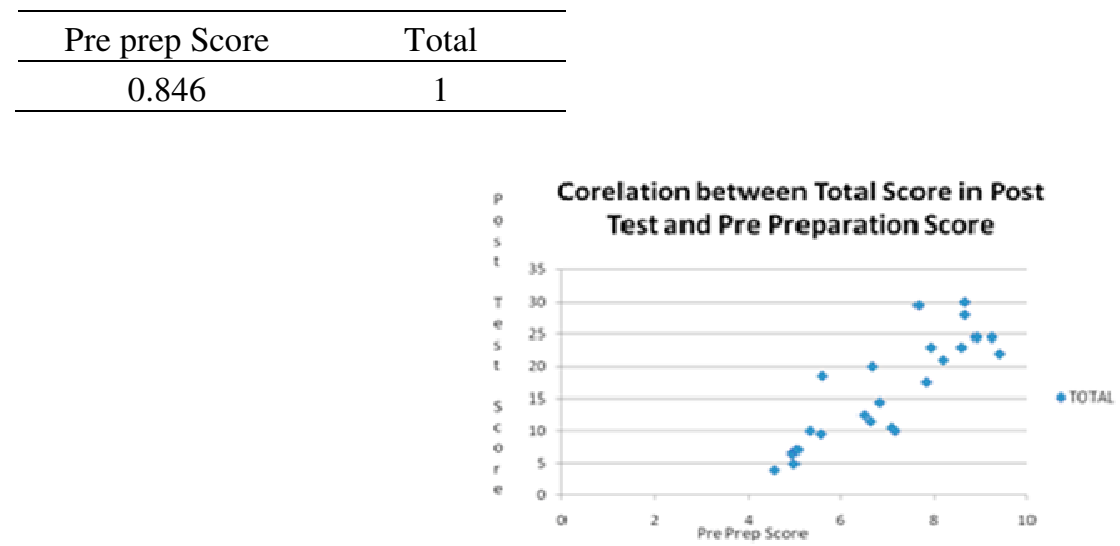

Figure 2. Total Score against Pre Prep Score

The attendance percentage of students was also calculated. The purpose of analyzing the student attendance of both groups was to observe if students are more regular in attending the inverted class room sessions that traditional ones. Results (Table 5) confirmed that this was indeed the case as the null hypothesis was rejected. Descriptive Statistics results (Table 7) were derived from a questionnaire given out to inverted class room students at the end of the course. The objective was to gain more insight into the perception of the students regarding pre-preparation material, their learning though this methodology and the overall course experience. Responses were collected on a Likert scale with 5 indicating strong agreement and 1 for strong disagreement to the statements. 
A study of inverted classroom pedagogy in computer science teaching

The results of this questionnaire were compiled and analyzed in three areas.

- Course Experience: Student feedback of the overall environment of this mode of study.

- Learning Effectiveness: Student perception of if they learnt better in this environment.

- Pre preparation Quality: The degree to which the study materials provided to the students were accessed and found satisfactory.

The descriptive analysis (Table 7) of their responses showed that students were positively inclined towards this pedagogy. This held true for all three areas mentioned above.

\section{Table 7}

Descriptive Statistical Analysis of Questionnaire Data

\begin{tabular}{lccc}
\hline & Course Experience & Learning Effectiveness & Pre preparation Quality \\
\hline Mean & 3.63 & 3.49 & 3.68 \\
Standard Error & 0.16 & 0.17 & 0.16 \\
Median & 3.83 & 3.5 & 3.67 \\
Mode & 4.5 & 4 & 3.67 \\
Standard Deviation & 0.76 & 0.81 & 0.75 \\
Sample Variance & 0.57 & 0.66 & 0.56 \\
Range & 2.5 & 3.5 & 3 \\
Minimum & 2.0 & 1.25 & 2 \\
Maximum & 4.5 & 4.75 & 5 \\
\hline
\end{tabular}

\section{Observations}

The above results (Table 4) clearly indicate that the learning of students on most parameters (problem solving ability, programming ability and the overall score) was much enhanced for the experiment group than for the control group. The gain in theoretical knowledge on the other hand does not show a significant difference in both the groups. The main reason for these results seem to be that since the inverted class room methodology is basically a hands-on environment therefore students were more able to improve their practical skills in this course. The theoretical part of the course was covered by students themselves mainly with only short discussion time devoted to such concepts in class. It therefore seems reasonable that the students did not surpass the traditional class room students in this area.

In the problem solving and programming abilities areas on the other hand there is a marked difference in the scores achieved by inverted class room students and those of the control group. The inverted class room students show a much better performance. A number of reasons provide a justification for this result. Firstly since the class room time was mainly devoted to problem solving and programming problems therefore it seems natural that the students felt confident and did well in that type of questions in the post-test as well.

Secondly, since the students came to class after having studied the material at least once and after having attempted the review questions, they gained specific insight as to what part of the content was unclear to them. Therefore, it was witnessed that the questions they asked were much more focused, more relevant and of a higher learning value than what students generally asked in the control group.

\section{Discussion}

Typically Data Structures had the reputation of being a tough, programming oriented course. However this enthusiasm of the researcher's inverted class room students intrigued other traditional class room students and they came with requests to be allowed to sit in this class; however their request could not be accepted as it would 
have spoiled the design of this study. 9 out of 43 students of the control group requested to be dropped from the course immediately before the midterm exam. Only 2 out of 23 students of the experiment group came up with this request. Thus the course drop rate in control group was $21 \%$ while that in the experiment group as $8.6 \%$ only. This research has therefore endorsed the results of previous studies thereby providing a basis to perform a conversion to this methodology in undergraduate teaching.

The results of this research can be utilized by educationists in general and computer science faculty, in particular. Since such a study had not been conducted in Pakistan earlier, it has helped to determine how the students of computer science in this country can gain the maximum benefit from the curriculum as well as the expertise of the teachers. It can be utilized by governing bodies like Higher Education Commission in Pakistan to focus not only on the curriculum and other aspects of teaching but also to provide opportunities to apply new teaching methodologies that will help in imparting education. This research is expected to open avenues of research in other fields of education. Mostly students have benefitted from this result as they have been exposed to better learning environments through which they were able to learn and grasp more knowledge. Faculty of these disciplines will also find it useful to convert their existing courses to inverted class room methodology using the results of this research.

Major contributions of this study are that it determined that students do learn better through a course offered in an inverted class room environment as compared to one offered in a traditional class room. The use of this environment had a huge impact on improving the programming and problem solving skills of students. It established that students were keener to attend classes offered in this mode as it kept them engaged and attentive throughout the class time. The use of this methodology had a positive impact on students' attendance in class. Students' perception of their experience in an inverted classroom was very positive as well.

\section{Conclusion and recommendations}

The inverted class room pedagogy had not been researched earlier at undergraduate universities in Pakistan for a Computer Science Course. The above study has shown positive results regarding its use in this context. These results are in agreement with the results of similar studies held earlier in other parts of the world. This teaching environment holds the potential of making this field of study more interesting, motivating for the student if followed correctly. Students usually are apprehensive from the practical aspects of Programming and Data Structure courses. If taught in this manner, this study has proved that they will become more skillful in these courses. Therefore, it is recommended that all practical courses in the Bachelor of Science in Computer Science (BSCS) curriculum should be converted to blended form and taught using inverted classrooms. Research on this topic can be extended further by studying how a standard model can be developed to convert a traditional computer science course to an inverted course. Other aspects include research on the choice of medium to use for imparting lecture content.

\section{References}

Carlisle, M. C. (2010, June). Using YouTube to enhance student class preparation in an introductory Java course. Paper Presented at the Conference of Technical Symposium on Computer science education, New York, USA.

Carrington, D., Kim, S. K., \& Strooper, P. (2010, March). An experience report on using collaboration technologies for distance and on-campus learning. Paper Presented at the Conference of Australasian Computing Education, Brisbane, Australia.

Day, J. A., \& Foley, J. D. (2006). Evaluating a web lecture intervention in a human computer interaction course. Institute of Electrical and Electronics Engineers Transactions on Education, 49(4), 420-431.

Fonseca, P., Casas, P. J., Rodriguez, S. V., \& Faulin, J. (2009, June). Simulation education in the internet age: Some experiences on the use of pure online and blended learning model. Paper Presented at the Winter Simulation Conference, Washington D.C., USA. http://dx.doi.org/10.1109/wsc.2009.5429336 
A study of inverted classroom pedagogy in computer science teaching

Foreman, J. (2003). Next-generation educational technology versus the lecture. Educause Review, 38(4), 12-22.

Gal-Ezer, J. (2009). Different models of course development: From traditional distance education to technology based education. Technical Symposium on Computer Science Education, 41(2), 77-78. http://dx.doi.org/10.1145/1595453.1595473

Gannod, G. C., Burge, J. E., \& Helmick, M. T. (2008, May). Using the inverted classroom to teach software engineering. Paper Presented at International Conference on Software Engineering, New York, USA. http://dx.doi.org/10.1145/1368088.1368198

Garner, S., Haden, P. J., \& Robins, A. (2005, September). My program is correct but it doesn't run: A preliminary investigation of novice programmers problems. Paper Presented at Computing Education Conference, Dunedin, New Zealand.

Hiltz, S. R., \& Turoff, M. (2005). Education goes digital: The evolution of online learning and the revolution in higher education. Communications of the Association of Computing Machinery, 48(10), 60-61. http://dx.doi.org/10.1145/1089107.1089139

Lage, M. J., Platt, G. J., \& Treglia, M. (2000). Inverting the classroom: A gateway to creating an inclusive learning environment. Journal of Economic Education, 31(1), 30-43. http://dx.doi.org/10.1080/00220480009596759

McCray, G. E. (2000). The hybrid course: Merging on-line instruction and the traditional classroom. Information Technology and Management, 1(4), 307-327. http://dx.doi.org/10.1023/A:1019189412115

Scheines, R., Leinhardt, G., Smith, J., \& Cho, K. (2005). Replacing lecture with web-based course materials. Journal of Educational Computing Research, 32(1), 1-25. http://dx.doi.org/10.2190/F59B-382T-E785-E4J4

Thille, C. (2010, March). Educational technology as a transformational innovation. Paper Presented at the Conference of White House Summit on Community Colleges, Washington D.C., USA. 
Appendix

\section{Questionnaire}

Please rate the following statements by the value from $1=$ strongly disagree to $5=$ strongly agree; use the values in between to graduate your opinion.

\begin{tabular}{|c|c|c|c|c|c|c|}
\hline & Statements & $\begin{array}{l}\frac{\lambda}{000} \\
\stackrel{0}{0} \\
\stackrel{\Xi}{\infty}\end{array}$ & 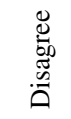 & 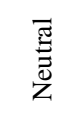 & 总 & 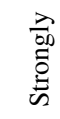 \\
\hline 1 & I enjoyed the inverted class experience in this course. & 1 & 2 & 3 & 4 & 5 \\
\hline 2 & $\begin{array}{l}\text { I would like to have other courses taught with the inverted class room } \\
\text { methodology. }\end{array}$ & 1 & 2 & 3 & 4 & 5 \\
\hline 3 & I had enough time to practice the relevant new skills in class & 1 & 2 & 3 & 4 & 5 \\
\hline 4 & I felt supported when practicing relevant new skills in class & 1 & 2 & 3 & 4 & 5 \\
\hline 5 & I prefer class activities over doing traditional homework. & 1 & 2 & 3 & 4 & 5 \\
\hline 6 & $\begin{array}{l}\text { I feel that teaching and learning outcomes were achieved very effectively with } \\
\text { this pedagogy. }\end{array}$ & 1 & 2 & 3 & 4 & 5 \\
\hline 7 & I had the opportunity to review my own misconceptions & 1 & 2 & 3 & 4 & 5 \\
\hline 8 & $\begin{array}{l}\text { The inverted class provided preparation for the class tests and other graded } \\
\text { activities }\end{array}$ & 1 & 2 & 3 & 4 & 5 \\
\hline 9 & $\begin{array}{l}\text { I always prepared myself through the study material before coming to class } \\
\text { room }\end{array}$ & 1 & 2 & 3 & 4 & 5 \\
\hline 10 & I normally attempted all review questions given with the preparatory material & 1 & 2 & 3 & 4 & 5 \\
\hline 11 & The website was helpful for my understanding & 1 & 2 & 3 & 4 & 5 \\
\hline
\end{tabular}

